\title{
Boron-Catalyzed C3-Polymerization of $\omega$-2-Methyl Allylarsonium Ylide and Its C3/C1 Copolymers with Dimethylsulfoxonium Methylide
}

\author{
De Wang, Zhen Zhang and Nikos Hadjichristidis* \\ King Abdullah University of Science and Technology (KAUST), Physical Science and Engineering \\ Division, KAUST Catalysis Center, Polymer Synthesis Laboratary, Thuwal 23955, Saudi Arabia \\ E-mail: nikolaos.hadjichristidis@kaust.edu.sa
}

\section{Experiment Section}

\section{Instruments:}

High temperature size exclusion chromatography (HT-SEC) measurements were carried out on a Viscoteck HT-GPC module 350 instrument with two PLgel $10 \mu \mathrm{m}$ MIXED-B columns using 1,2,4trichlorobenzene (TCB) as eluent at a flow rate of $0.8 \mathrm{~mL} / \mathrm{min}$ at $150{ }^{\circ} \mathrm{C}$ or Agilent PL-GPC 220 with one PLgel $10 \mu \mathrm{m}$ MIXED-B column using TCB as eluent at a flow rate of $1.0 \mathrm{~mL} / \mathrm{min}$ at $150{ }^{\circ} \mathrm{C}$. Both systems were calibrated by PS standards. THF was used as eluent at flow rate of $1 \mathrm{~mL} / \mathrm{min}$ in the cases for the GPC studies at ambient conditions (measurements taken at $30^{\circ} \mathrm{C}$ ). The system was calibrated by PS standards prior to use. Fourier-transform infrared spectroscopy (FTIR) (transmission) measurements were performed on a Nicolet Magna 6700 FT spectrometer. Differential scanning calorimetry (DSC) was performed on a Mettler Toledo DSC1/TC100 system under inert nitrogen atmosphere. The samples were heated from room temperature to $140{ }^{\circ} \mathrm{C}$, cooled to $-100{ }^{\circ} \mathrm{C}$ and finally heated again to $140{ }^{\circ} \mathrm{C}$ at a heating/cooling rate of 10 ${ }^{\circ} \mathrm{C} / \mathrm{min}$. The second heating curve was used to determine the glass transition temperature $\left(\mathrm{T}_{\mathrm{g}}\right)$, melting temperature $\left(\mathrm{T}_{\mathrm{m}}\right)$ and degree of crystallinity. Crystallinity $\mathrm{X}_{\mathrm{c}}=\Delta \mathrm{H}_{\mathrm{m}} / \Delta \mathrm{H}_{\mathrm{m}}{ }^{+}$, where $\Delta \mathrm{H}_{\mathrm{m}}\left(288 \mathrm{~kJ} \mathrm{~kg}^{-1}\right)$ is the specific enthalpy of melting for $100 \%$ crystalline PE.

\section{Chemicals:}

$n$-Butyllithium (n-BuLi) (1.6 M in hexane, Aldrich), calcium hydride $\left(\mathrm{CaH}_{2}\right)$ (95\%, Aldrich), trimethylsulfoxonium iodide (98\%, Alfa Asar), Benzyltri- $n$-butylammonium chloride (98\%, Alfa Aesar) and trimethylamine $\mathrm{N}$-oxide dihydrate $(\mathrm{TAO})(>99 \%$, Fluka) were used as received. Styrene and butadiene 
were purchased from Aldrich and distilled from $\mathrm{CaH}_{2}$ before use. Boron trifluoride diethyl etherate $\left(\mathrm{BF}_{3} \mathrm{OEt}_{2}\right)$ (purum, Fluka) was distilled from $\mathrm{CaH}_{2}$ prior to use. Sodium hydride (60\% dispersion in mineral oil, Acros) was washed with petroleum ether $\left(40-60{ }^{\circ} \mathrm{C}\right)$ prior to use. Methanol (99\%, Fisher), acetonitrile (99\%, Fisher), dichloromethane (>99\%, Fisher) were obtained from Fisher and used as received. Tetrahydrofuran (99\%, Fisher) and toluene (99.7\%, Fluka) were distilled from $\mathrm{CaH}_{2}$ prior to use.

\section{General method for preparing arsonium ylides:}

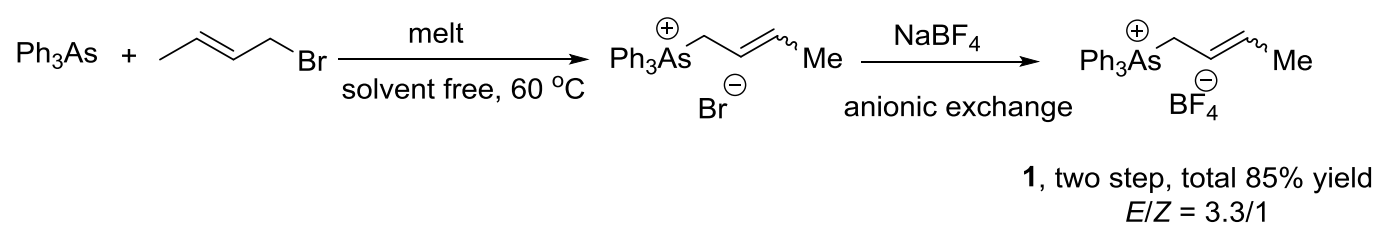

Scheme S1 Synthesis of two novel ylides

In a pre-heated dry flask, triphenylarsorine (20 mmol, $6.12 \mathrm{~g}, 1.0$ eq.) and crotyl bromide or cinnamyl bromide ( $24 \mathrm{mmol}, 1.2$ eq.) were added under argon. The mixture was heated at $60{ }^{\circ} \mathrm{C}$ and stirred without any solvent. After one hour, the melted liquid became solid. The heating was stopped and the mixture was cooled down to room temperature and $200 \mathrm{~mL}$ of $\mathrm{Et}_{2} \mathrm{O}$ were added to the solid and the solution was stirred for an additional hour (to wash and dissolve the un-react starting material). The solution was filtered; the desired solid was collected and dried under vacuum in order to obtain the but-2-en-1-yltriphenylarsonium bromide or cinnamyltriphenylarsonium bromide.

The desired compounds were diluted in dichloromethane (DCM) or chloroform (approximate $100 \mathrm{~mL}$ ), and aqueous solution of sodium tetrafluoroborate (30 eq.) was added to the organic phase. After two days of vigorous stirring, the aqueous solution was extracted with DCM and the combined organic layers were dried over $\mathrm{Na}_{2} \mathrm{SO}_{4}$. The solution was concentrated further on a rotary evaporator under reduced pressure in order to afford crude product 1. Further purification involved recrystallization (DCM/petroleum ether).

\section{NMR Data of arsonium ylide salt 1}

\section{Arsonium ylide salt 1:}

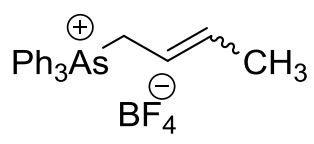

White solid, 85\% yield, Mp: 173.2-174.8 ${ }^{\circ} \mathrm{C} .{ }^{1} \mathrm{H}$ NMR (400 MHz, $\mathrm{CDCl}_{3}$, TMS) $\square$ 7.77-7.61 (m, $15 \mathrm{H}$, Ar), 5.91-5.84 (m, $1 \mathrm{H}, b, Z$ and $E$ ), 5.48-5.36 (m, $1 \mathrm{H}, c, 0.24 \mathrm{H}$ of $Z, 0.76 \mathrm{H}$ of $E$ ), 4.23 (d, J=8.0 Hz, 0.52 $\mathrm{H}$ of $Z, a), 4.17(\mathrm{~d}, J=8.0 \mathrm{~Hz}, 1.70 \mathrm{H}$ of $E, \mathrm{a}), 1.62(\mathrm{~d}, J=6.4 \mathrm{~Hz}, 2.55 \mathrm{H}$ of $E, \mathrm{Me}, d), 1.40(\mathrm{~d}, J=6.4 \mathrm{~Hz}$, 
$0.77 \mathrm{H}$ of $Z, \mathrm{Me}, d) ;{ }^{13} \mathrm{C}$ NMR $\left(100 \mathrm{MHz}, \mathrm{CDCl}_{3}\right) \square$ 137.67, 135.24, 134.20, 134.13, 132.75, 132.69, 130.87, 130.82, 120.94, 120.89, 115.87, 115.13, 29.17, 24.40, 18.17, 13.12; ${ }^{19} \mathrm{~F}$ NMR (175 $\left.\mathrm{MHz}, \mathrm{CDCl}_{3}\right)$ $\square-152.20,-152.25$; HRMS Calcd. for $\mathrm{C}_{22} \mathrm{H}_{22} \mathrm{As}^{+1}\left(\mathrm{M}-\mathrm{BF}_{4}\right)^{+}: 361.0930$.

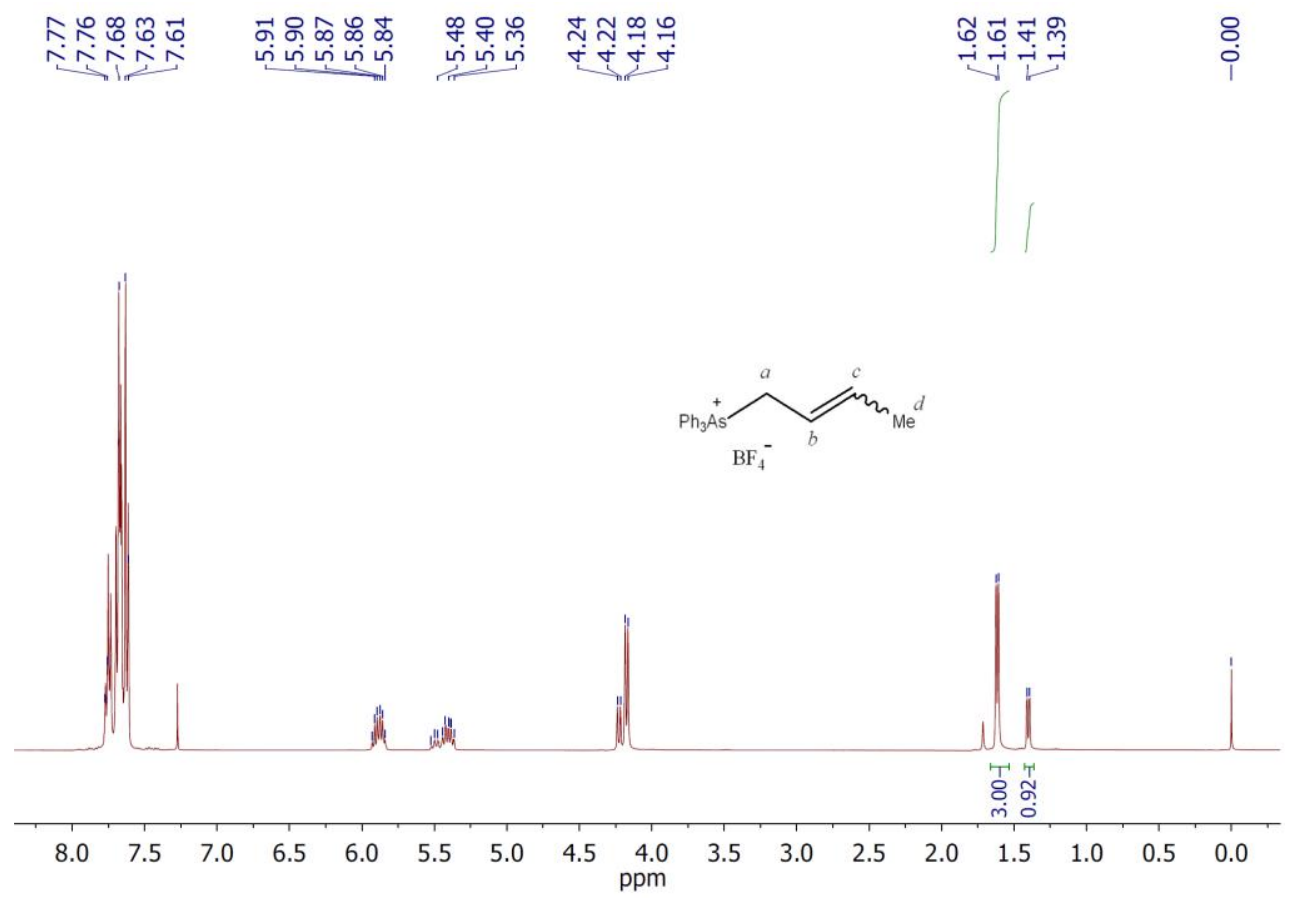

Figure S1. ${ }^{1} \mathrm{H}$ NMR spectrum of arsonium ylide salt $\mathbf{1}$

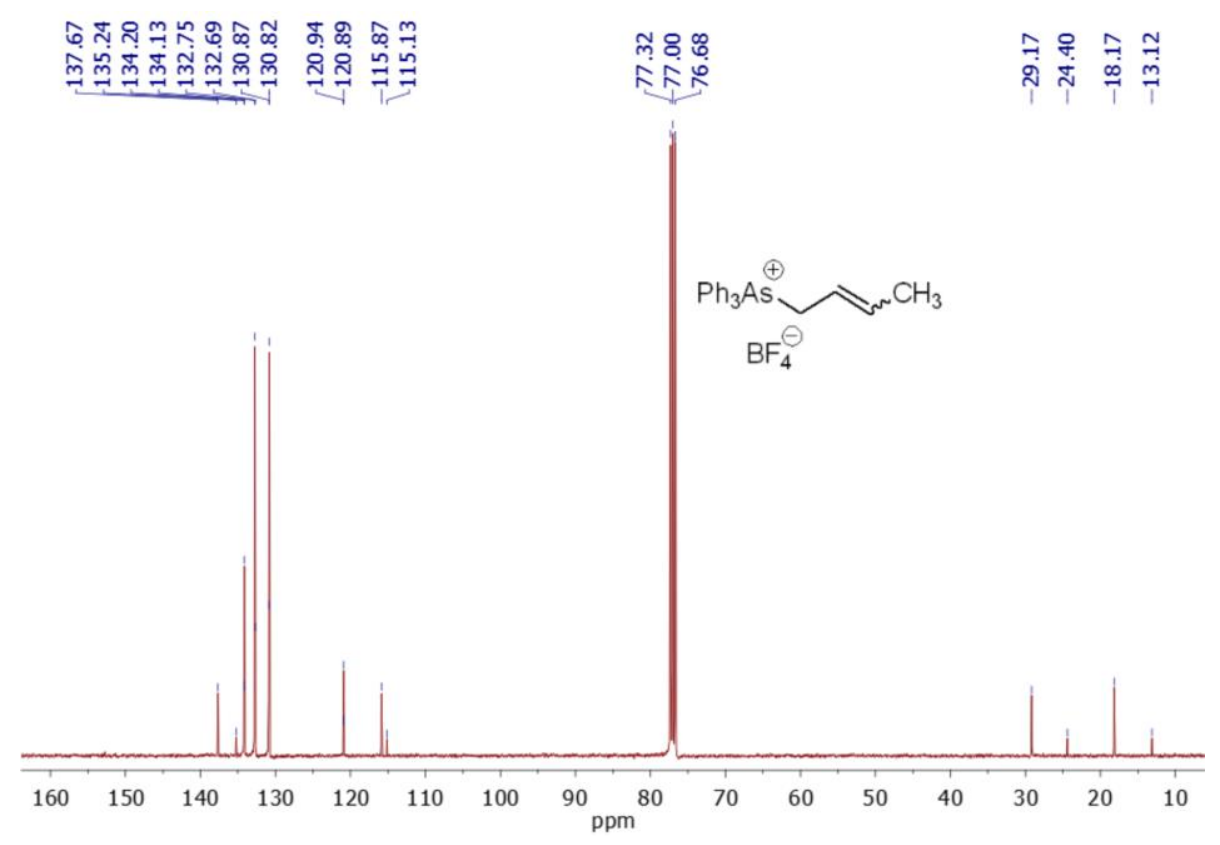

Figure S2. ${ }^{13} \mathrm{C}$ NMR spectrum of arsonium ylide salt $\mathbf{1}$ 


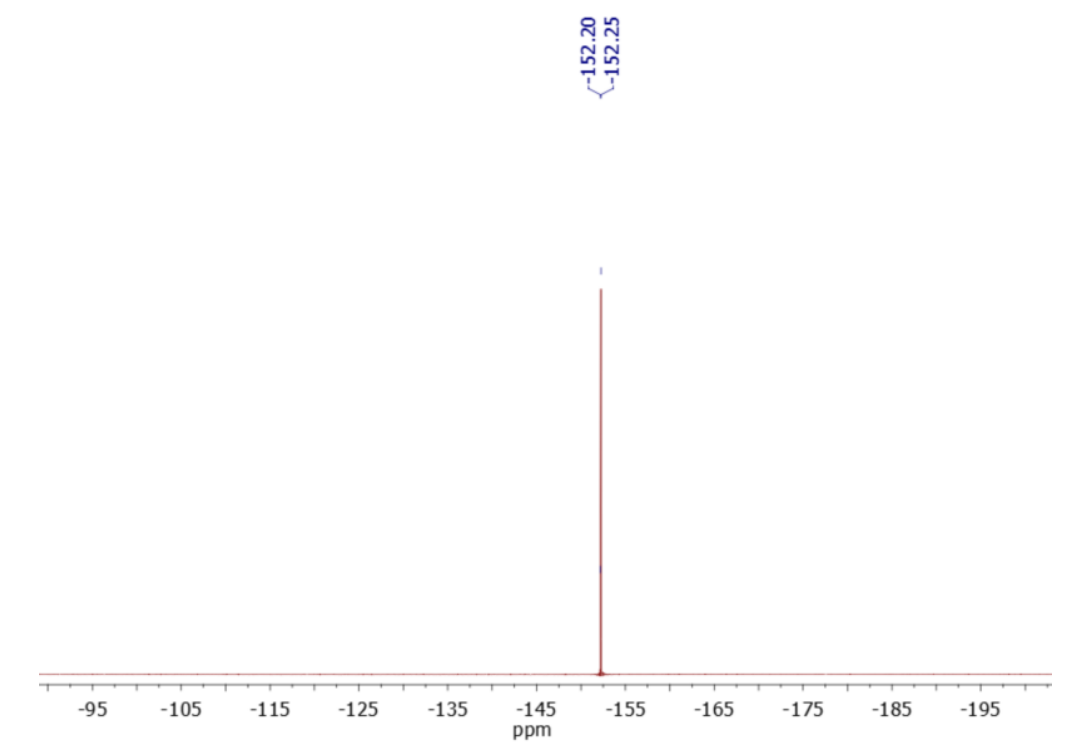

Figure S3. ${ }^{19} \mathrm{~F}$ NMR spectrum of arsonium ylide salt $\mathbf{1}$

\section{General polymerization of the methyl substituted allylic arsonium ylide 1}

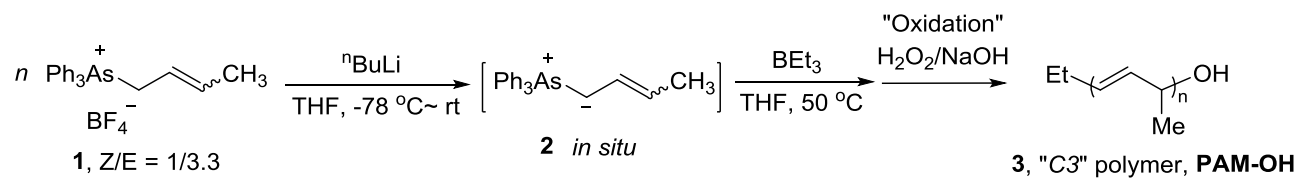

Scheme S2. Polymerization of ylide 1 with borane

Methyl substituted arsonium ylide salt 1 (1.6 mmol, $720 \mathrm{mg}$ ) was added into a Schlenk tube (pre-dried), then THF as solvent was added under argon. The suspension was cooled to $-78^{\circ} \mathrm{C}$, then n-butyllithium $(1.6$ $\mathrm{M}$ in hexane, $1.6 \mathrm{mmol}, 1.0 \mathrm{~mL}$ ) was added to the suspension solution slowly. After the addition of butyllithium, a clear and red solution was obtained. The red solution was allowed to warm up to room temperature slowly. At room temperature, $\mathrm{Et}_{3} \mathrm{~B}(1 \mathrm{M}$ in THF, $0.01 \mathrm{mmol}, 10 \mu \mathrm{L})$ was added to the red solution and then the mixture was heated at $50{ }^{\circ} \mathrm{C}$ immediately. After discoloration, $\mathrm{H}_{2} \mathrm{O}_{2} / \mathrm{NaOH}$ was added as oxidant and the solution was stirred at $50^{\circ} \mathrm{C}$ for 2 hours. The organic phase was collected and the solvent was removed under vacuum in order to obtain the solid. This solid was dissolved in dichloromethane (1-2 $\mathrm{mL}$ ), followed by addition into excess of $n$-hexane, filtered and washed with petroleum ether. Finally, by collecting the $n$-hexane and petroleum ether solution and removing the solvent under vacuum the desired polymer was obtained. 
(A)

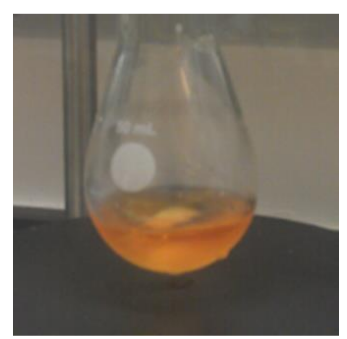

(B)

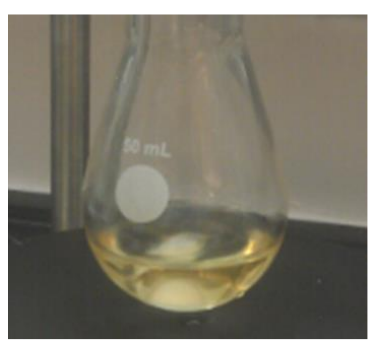

(C)

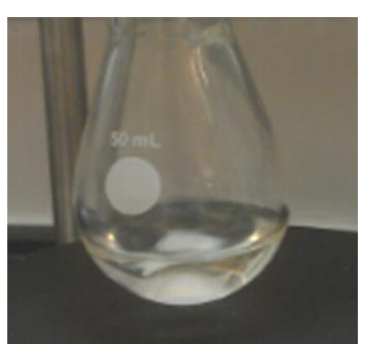

Figure S4. Before (A) and after (B) addition of borane; (C): after heating at $50{ }^{\circ} \mathrm{C}$ and cooling to room temperature

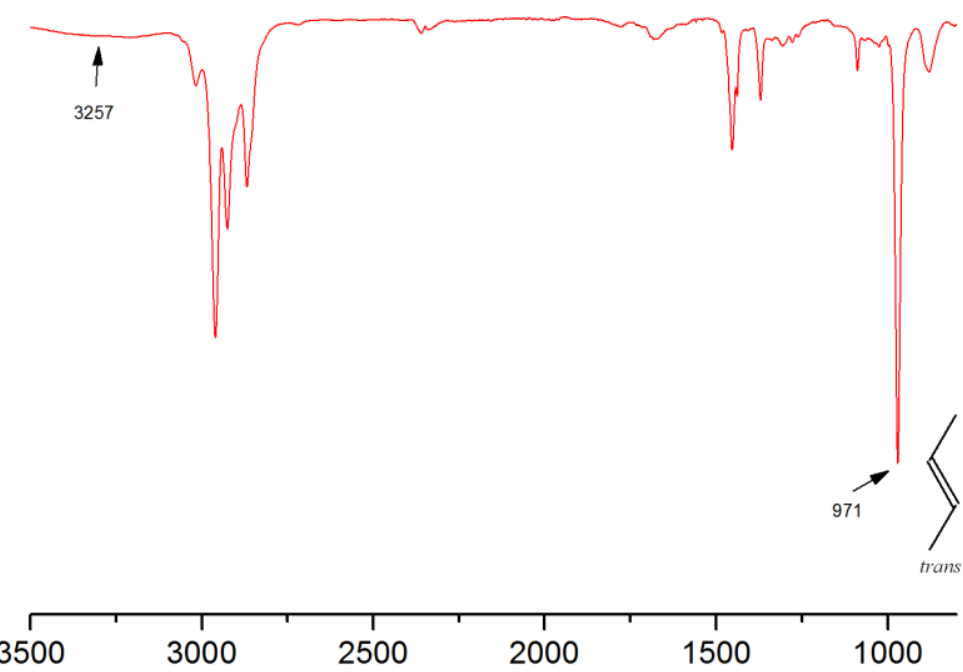

Figure S5. FT-IR of polymer 3: the signal at $971 \mathrm{~cm}^{-1}$ corresponds to trans double bond; the broad peak at $3257 \mathrm{~cm}^{-1}$ verifies the hydroxyl group. 


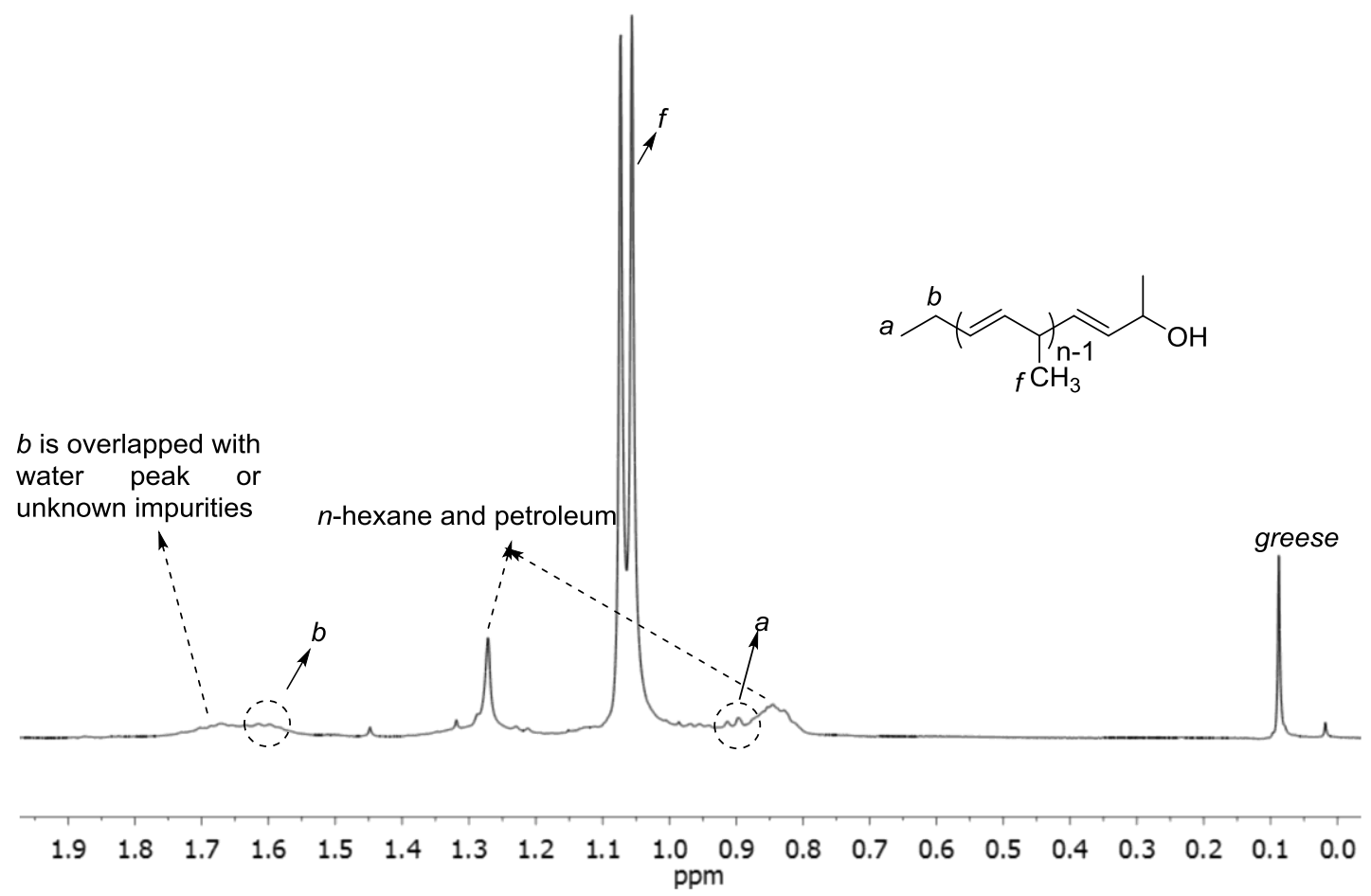

Figure S6. Enlarged part of polymer 3a spectrum to detect the terminal ethyl group (full spectrum is given in the main text Figure 1B).

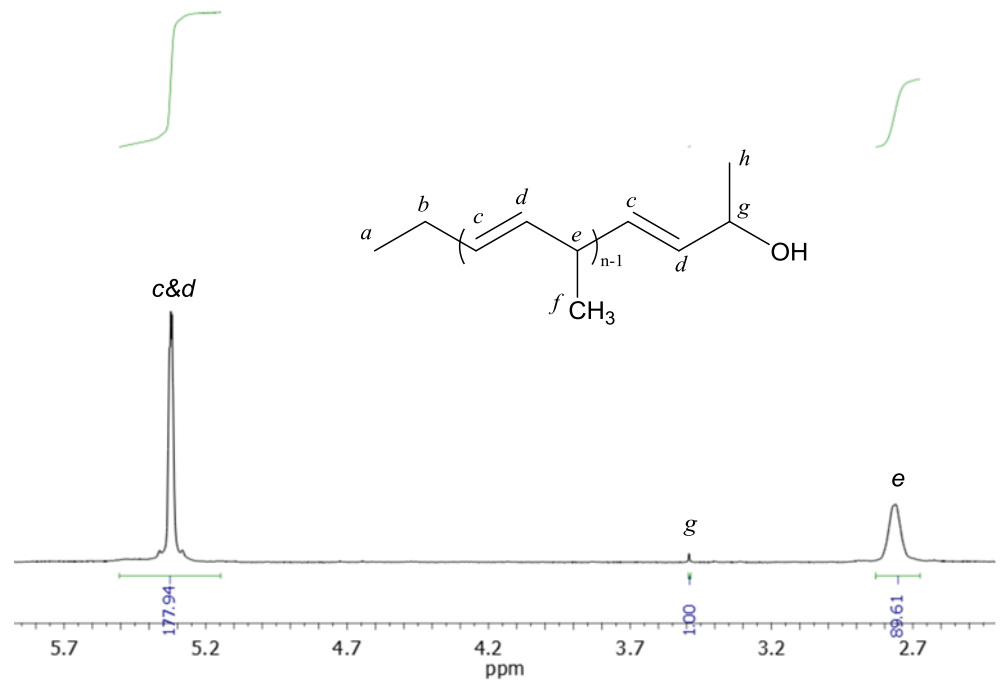

Figure S7. Enlarged part of spectrum of polymer 3a to calculate the degree of polymerization $\left(\mathrm{DP}_{\mathrm{NMR}}=\right.$ 90) by end group analysis (full spectrum is given in main text Figure 1B). 


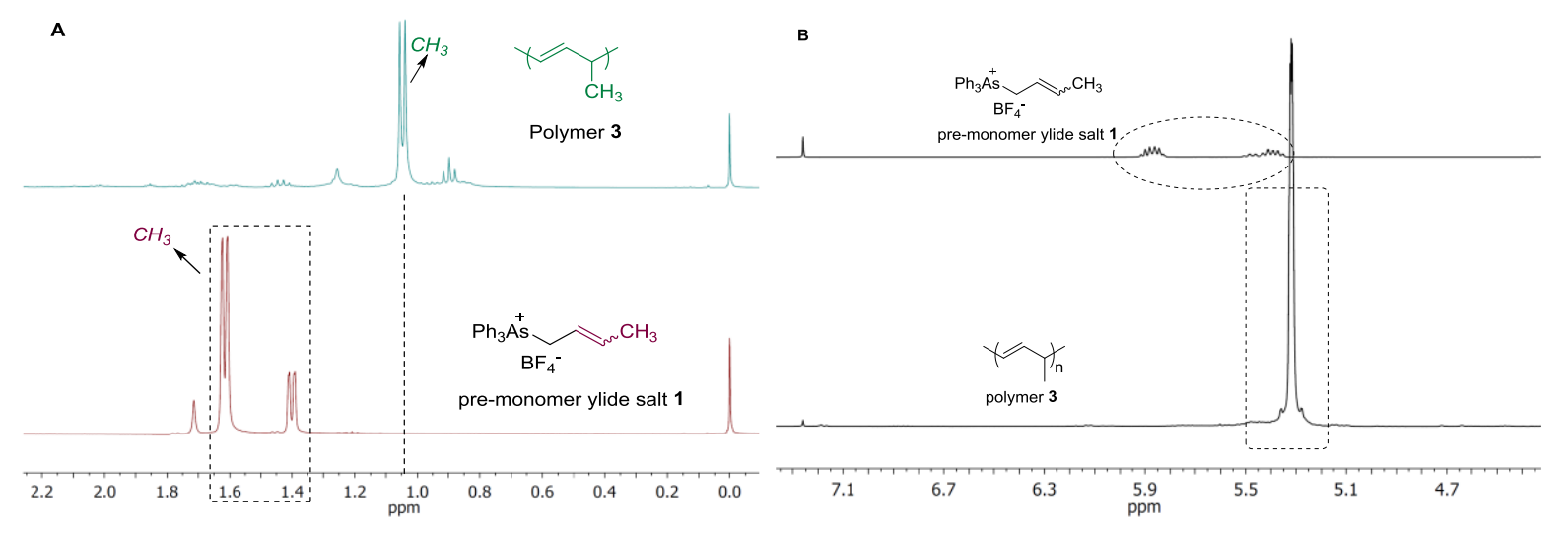

Figure S8. Form A: Methyl group connected to the double bond (pre-monomer ylide salt 1). The chemical shifts at $1.4 \mathrm{ppm}$ and $1.6 \mathrm{ppm}$ correspond to $Z$ and $E$ configurations respectively. For polymer $\mathbf{3}$, the chemical shift of methyl group changes to $\sim 1.05 \mathrm{ppm}$. This behaviour can be explained by the fact that methyl group is connected to the methylene $(\mathrm{CH})$. If the backbone of polymer $\mathbf{3}$ was containing exclusively

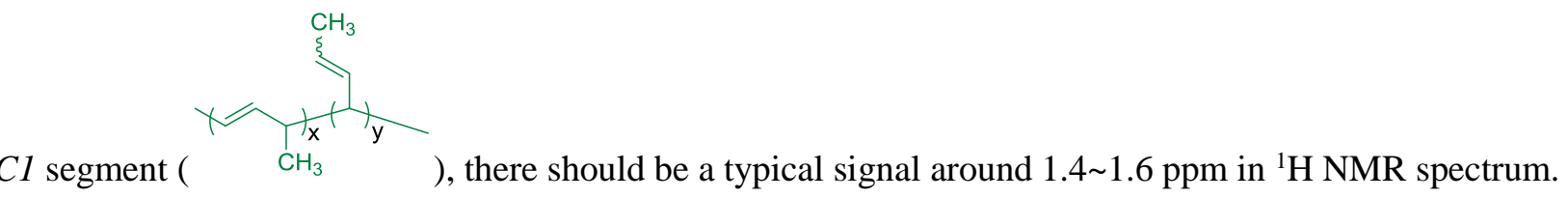
But the ${ }^{1} \mathrm{H}$ NMR of polymer 3 did not show any chemical shifts around 1.4 1.6 ppm corresponding to the methyl group. Form B: it is clear that the double bond is connected to the methyl is leading to two peak groups (alkene protons), while the polymer $\mathbf{3}$ double bond only have the one peak group. If the backbone

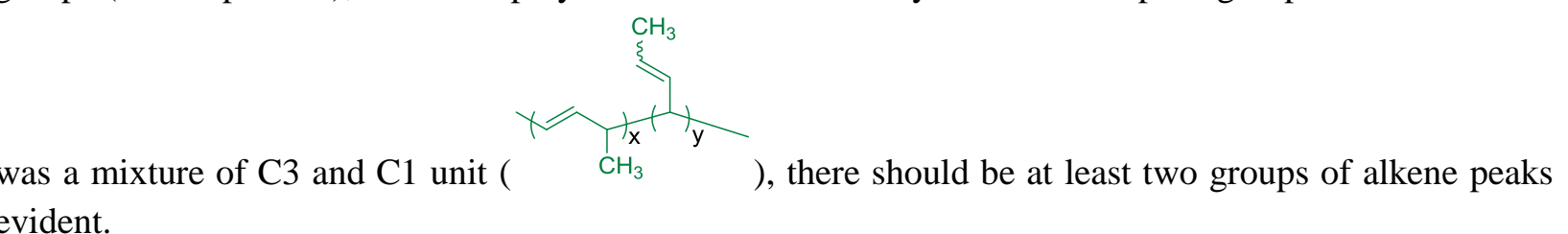
evident. 


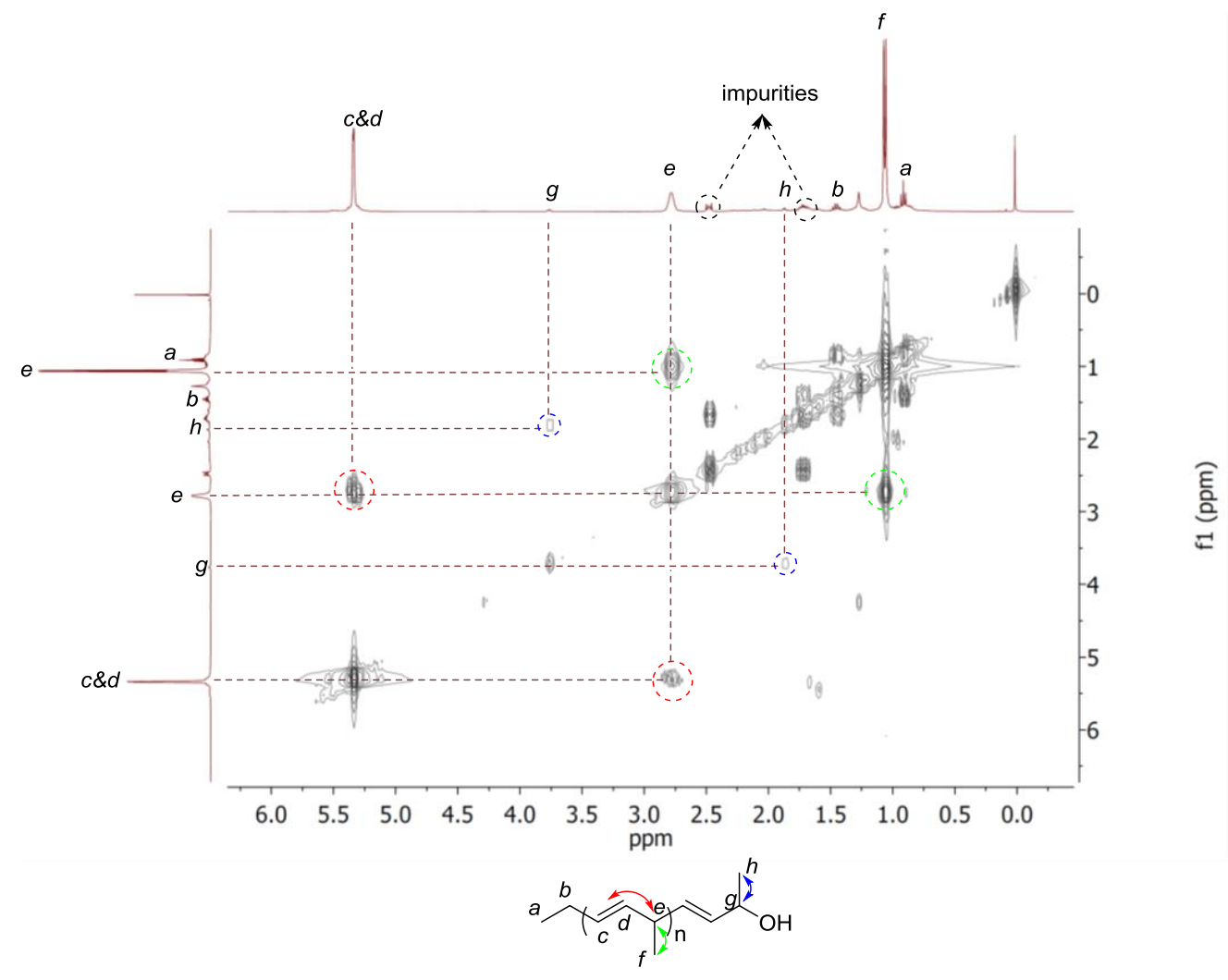

Figure S9. ${ }^{1} \mathrm{H}-{ }^{1} \mathrm{H}$ COSEY $\left(400 \mathrm{M}, \mathrm{CDCl}_{3}\right)$ of polymer 3. The main chain ethylenic protons " $c \& d$ " interact with the allylic methylene proton " $e$ " are labelled inside the red cycle; the allylic methylene proton " $e$ " interacts with the methyl group " $f$ " labelled inside the green cycle; the terminal allylic methylene proton " $g$ " interacts with the terminal methyl group " $h$ " labelled inside the blue cycle. The impurities might be originated from the minor excess of unreacted ylide salt after oxidation.

Table S1. Preparation of polymer 3 by using ylide 2 catalyzed by borane

\begin{tabular}{|c|c|c|c|c|c|c|c|c|}
\hline Entry $^{a}$ & Initiator & {$[\mathbf{M}] /[\mathbf{I}]$} & $\mathbf{D P}_{\text {cal }^{b}}$ & $\mathbf{D P}_{\mathrm{NMR}}{ }^{c}$ & $\begin{array}{c}M_{\mathrm{n}, \mathrm{NMR}}{ }^{c} \\
\times 10^{-3}\end{array}$ & $\begin{array}{r}M_{\mathrm{n}, \mathbf{G P C}^{d}} \\
\times 10^{-3}\end{array}$ & $\mathbf{P D I}^{d}$ & $\begin{array}{l}\text { Yield } \\
(\%)^{e}\end{array}$ \\
\hline 1 & $\mathrm{BEt}_{3}$ & $100 / 1$ & 33 & 36 & 2.1 & 4.1 & 1.28 & 62 \\
\hline 2 & $\mathrm{BEt}_{3}$ & $200 / 1$ & 67 & 98 & 5.3 & 8.3 & 1.24 & 71 \\
\hline 3 & $\mathrm{BH}_{3}$ & $200 / 1$ & 67 & 109 & 5.7 & 9.1 & 1.94 & 65 \\
\hline
\end{tabular}

${ }^{a}$ The polymerizations were carried out in THF at $20{ }^{\circ} \mathrm{C}$ with borane as initiator $(1 \mathrm{M})$ and heated at $50{ }^{\circ} \mathrm{C}$. ${ }^{b} \mathrm{DP}_{\text {cal }}$ was calculated by $[\mathrm{M}] / 3[\mathrm{I}] .{ }^{c} \mathrm{DP}_{\mathrm{NMR}}$ and $M_{\mathrm{n}, \mathrm{NMR}}$ were calculated by ${ }^{1} \mathrm{H}$ NMR spectra end group analysis $\left(\mathrm{CDCl}_{3}, \mathrm{TMS}\right){ }^{d}$ GPC (THF) results are given by calibration with polystyrene as standards. ${ }^{e}$ Isolated yield after three times precipitated from $n$-hexane and petroleum ether $\left(\mathrm{Ph}_{3} \mathrm{As}\right.$ and its oxidant product did not dissolve in $n$-hexane or petroleum ether, thus can be easily removed). 


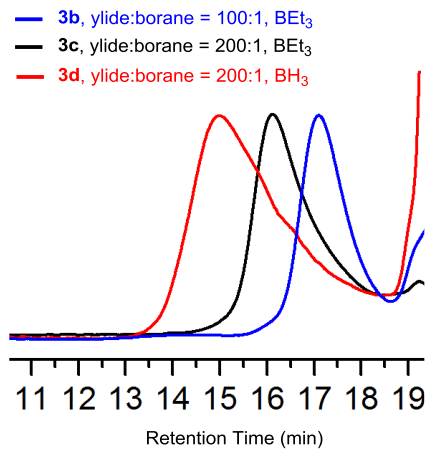

Figure S10. GPC (THF, polystyrene standards) traces corresponding to entry 1 (blue), entry 2 (black) and entry 3 (red) as given in Table $\mathrm{S} 1$.

${ }^{1} \mathrm{H}$ NMR spectra of polymers $\mathbf{3 b} \mathbf{b} \mathbf{3} \mathbf{d}$ (Table S1) after one precipitation

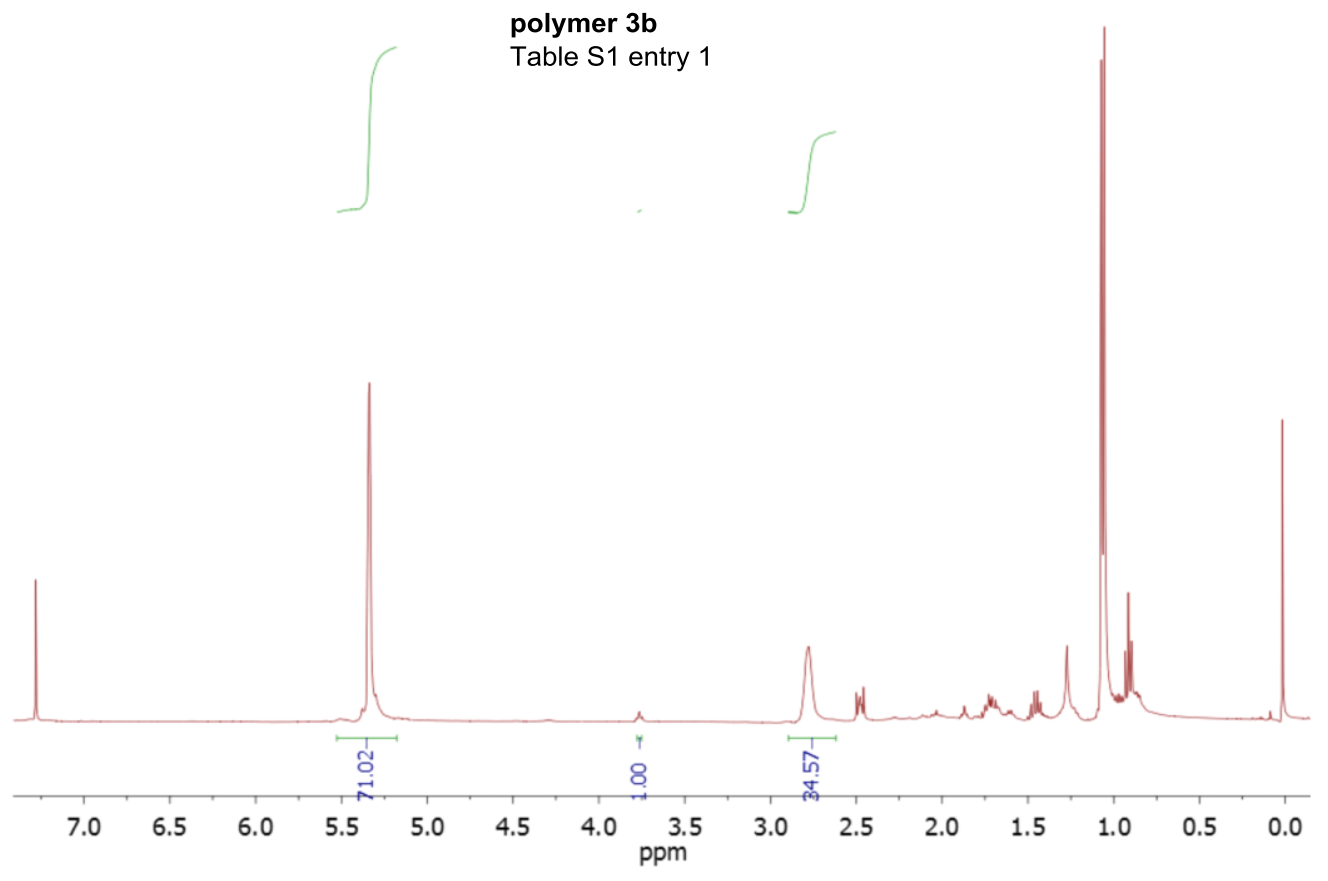

Figure S11. ${ }^{1} \mathrm{H}$ NMR spectrum $\left(400 \mathrm{M}, \mathrm{CDCl}_{3}\right)$ of polymer $\mathbf{3 b}\left(\mathrm{DP}_{\mathrm{NMR}}=36\right)$ 


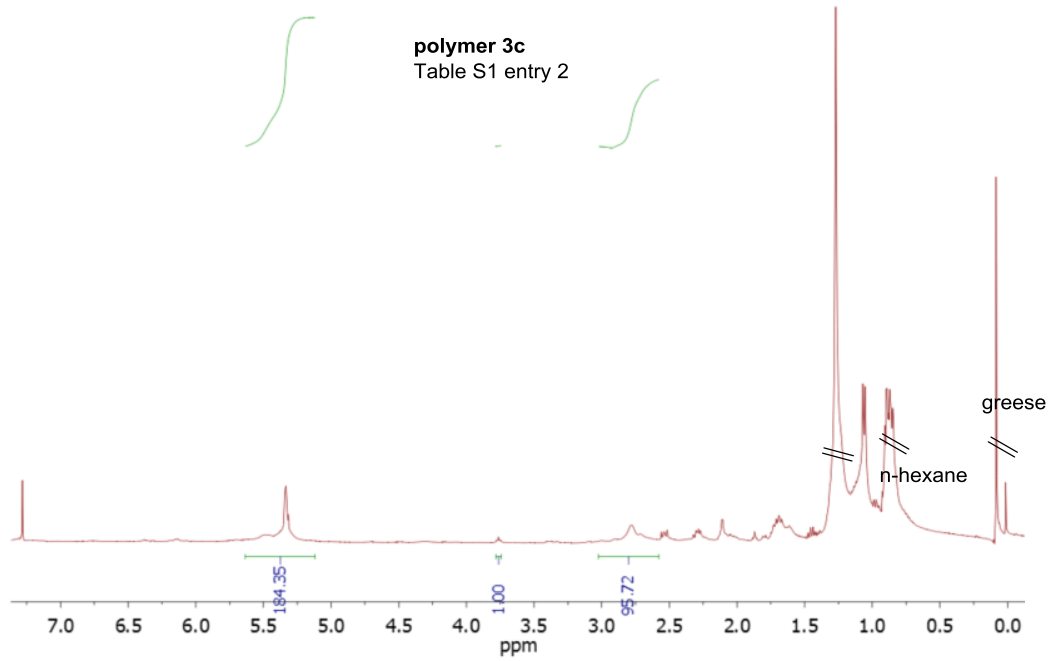

Figure S12. ${ }^{1} \mathrm{H}$ NMR spectrum $\left(400 \mathrm{M}, \mathrm{CDCl}_{3}\right)$ of polymer $3 \mathrm{c}\left(\mathrm{DP}_{\mathrm{NMR}}=97\right)$

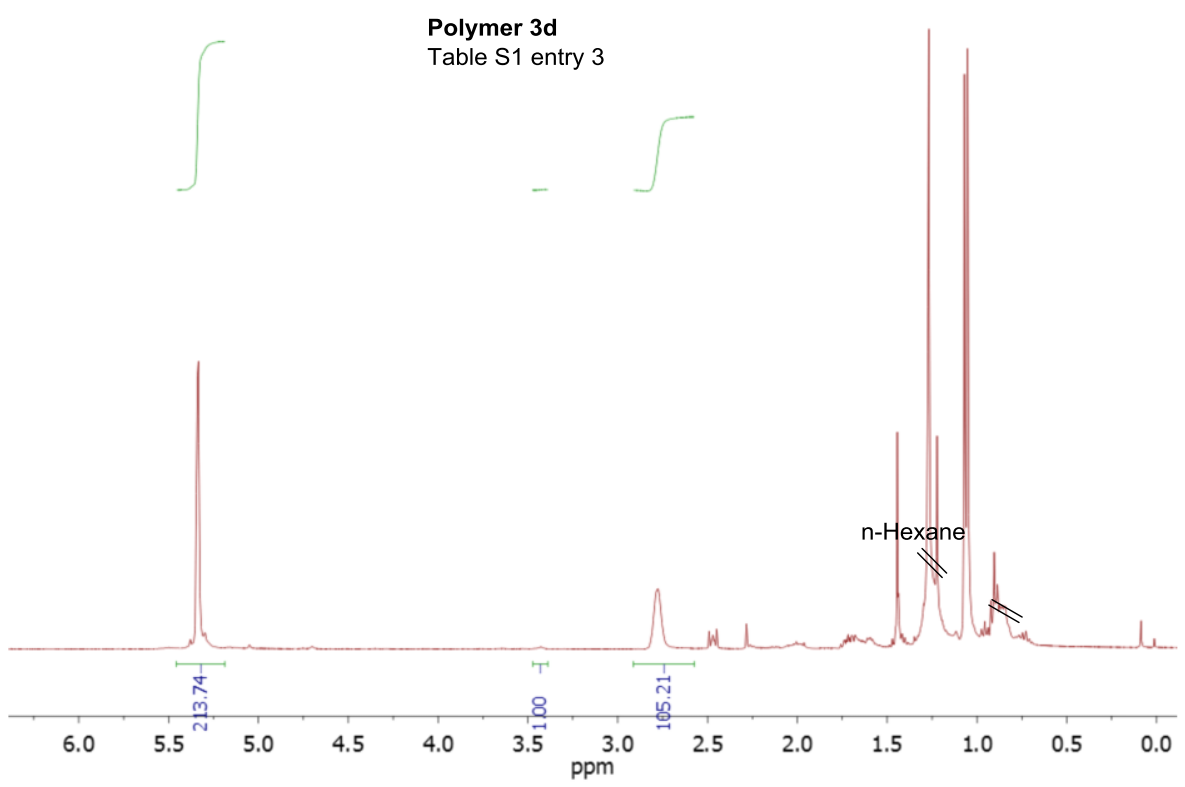

Figure S13. ${ }^{1} \mathrm{H}$ NMR spectrum $\left(400 \mathrm{M}, \mathrm{CDCl}_{3}\right)$ of polymer $3 \mathrm{c}\left(\mathrm{DP}_{\mathrm{NMR}}=106\right)$

${ }^{1} \mathrm{H}$ NMR spectra of Copolymers 7, 8 and $\mathbf{9 :}$ 


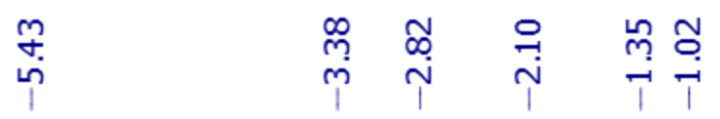

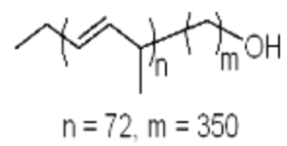

\begin{tabular}{llllllllllll}
\hline 9.5 & 8.5 & 7.5 & 6.5 & 5.5 & $\begin{array}{l}4.5 \\
\mathrm{ppm}\end{array}$ & 3.5 & 2.5 & 1.5 & 0.5 & -0.5
\end{tabular}

Figure S14. ${ }^{1} \mathrm{H}$ NMR spectrum $\left(600 \mathrm{M}\right.$, D8-toluene, $\left.80^{\circ} \mathrm{C}\right)$ of block copolymer $7(\mathrm{n}=72, \mathrm{~m}=350$, end group analysis) 


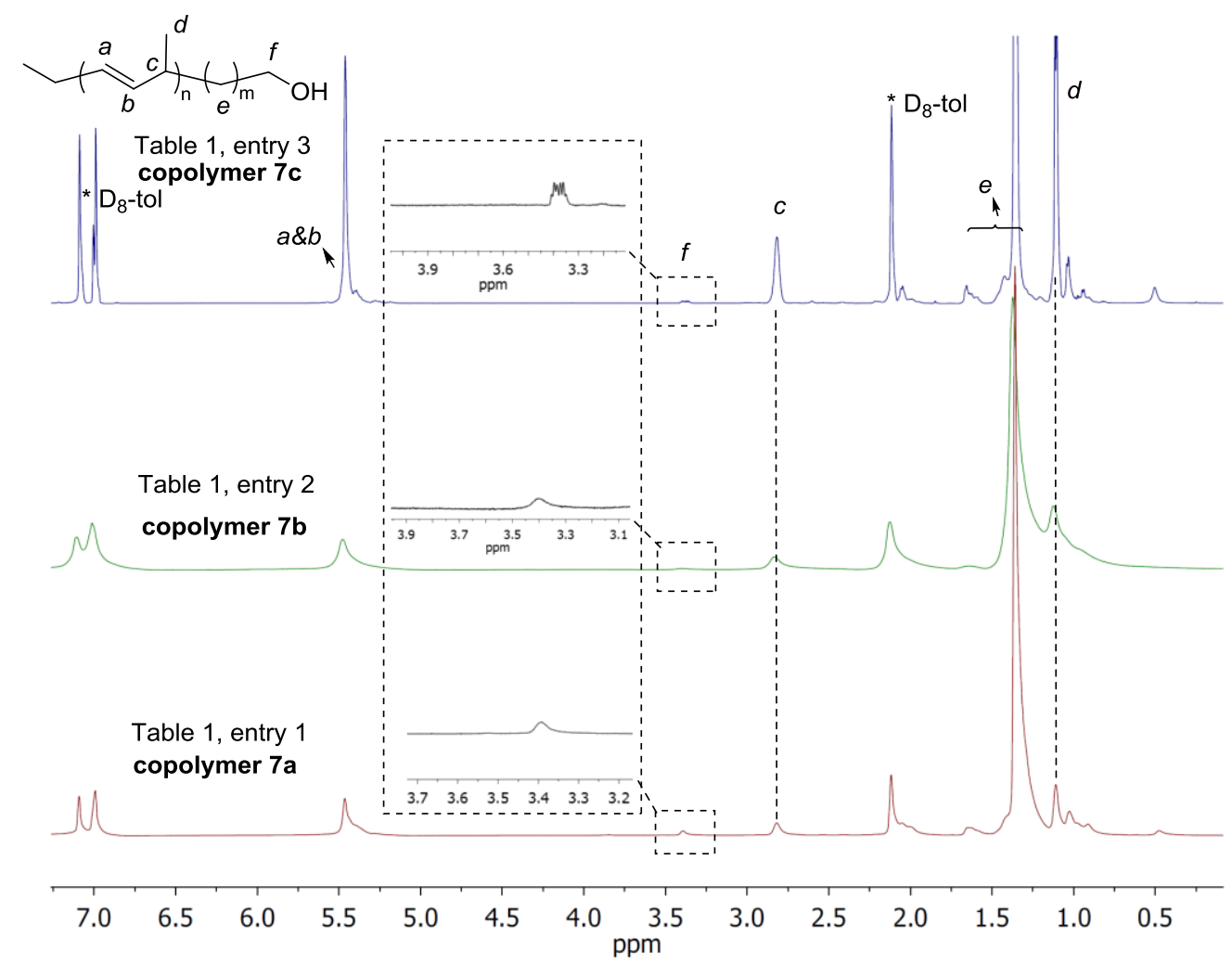

Figure S15. The ${ }^{1} \mathrm{H}$ NMR spectra $\left(600 \mathrm{M}, \mathrm{D} 8\right.$-toluene, $\left.80^{\circ} \mathrm{C}\right)$ for entries 1,2 and 3 as given in Table 1 of the main manuscript.

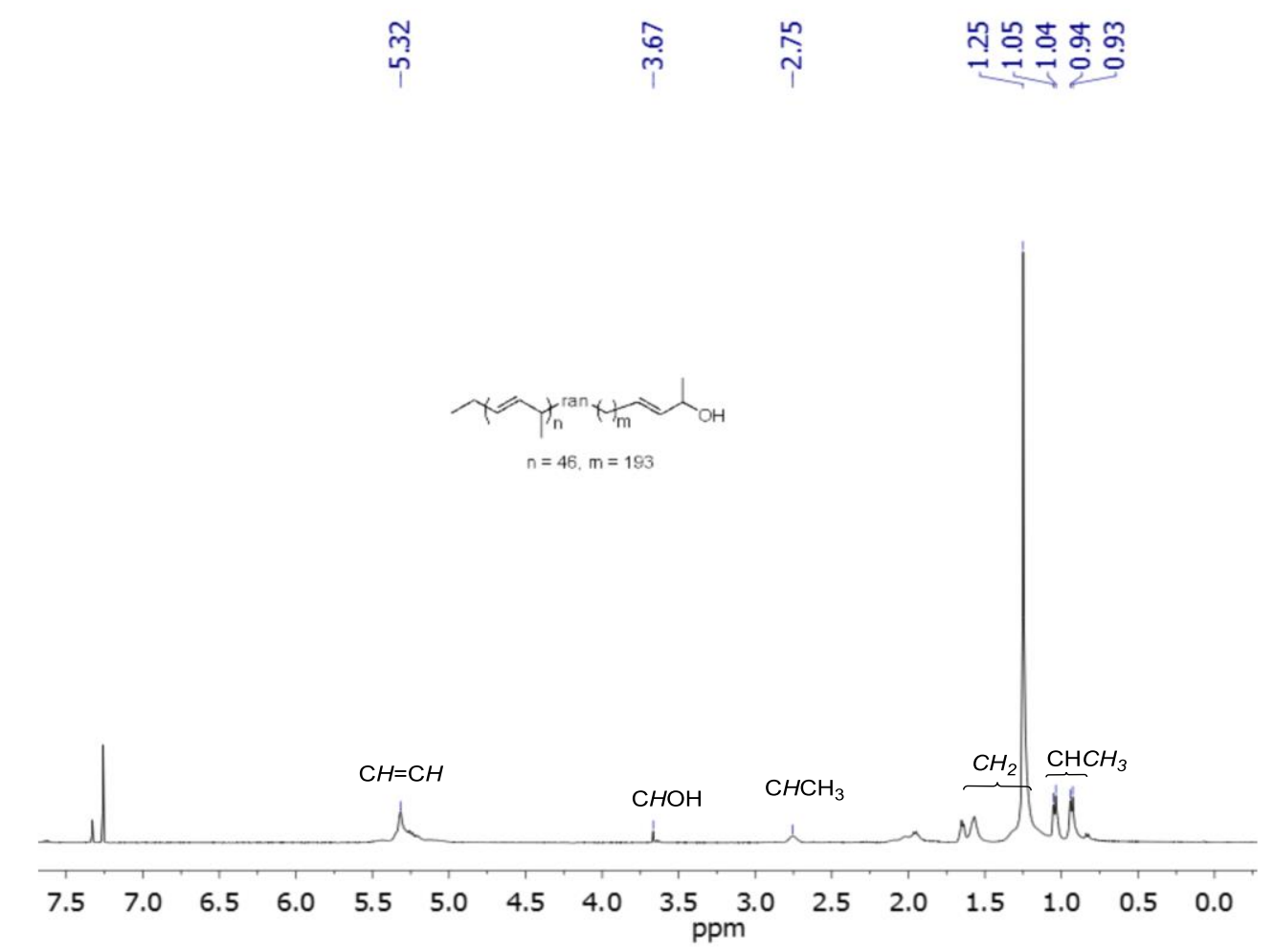

Figure S16. ${ }^{1} \mathrm{H}$ NMR spectrum $\left(400 \mathrm{M}, \mathrm{CDCl}_{3}\right)$ of random copolymer $8(\mathrm{n}=46, \mathrm{~m}=193)$ 


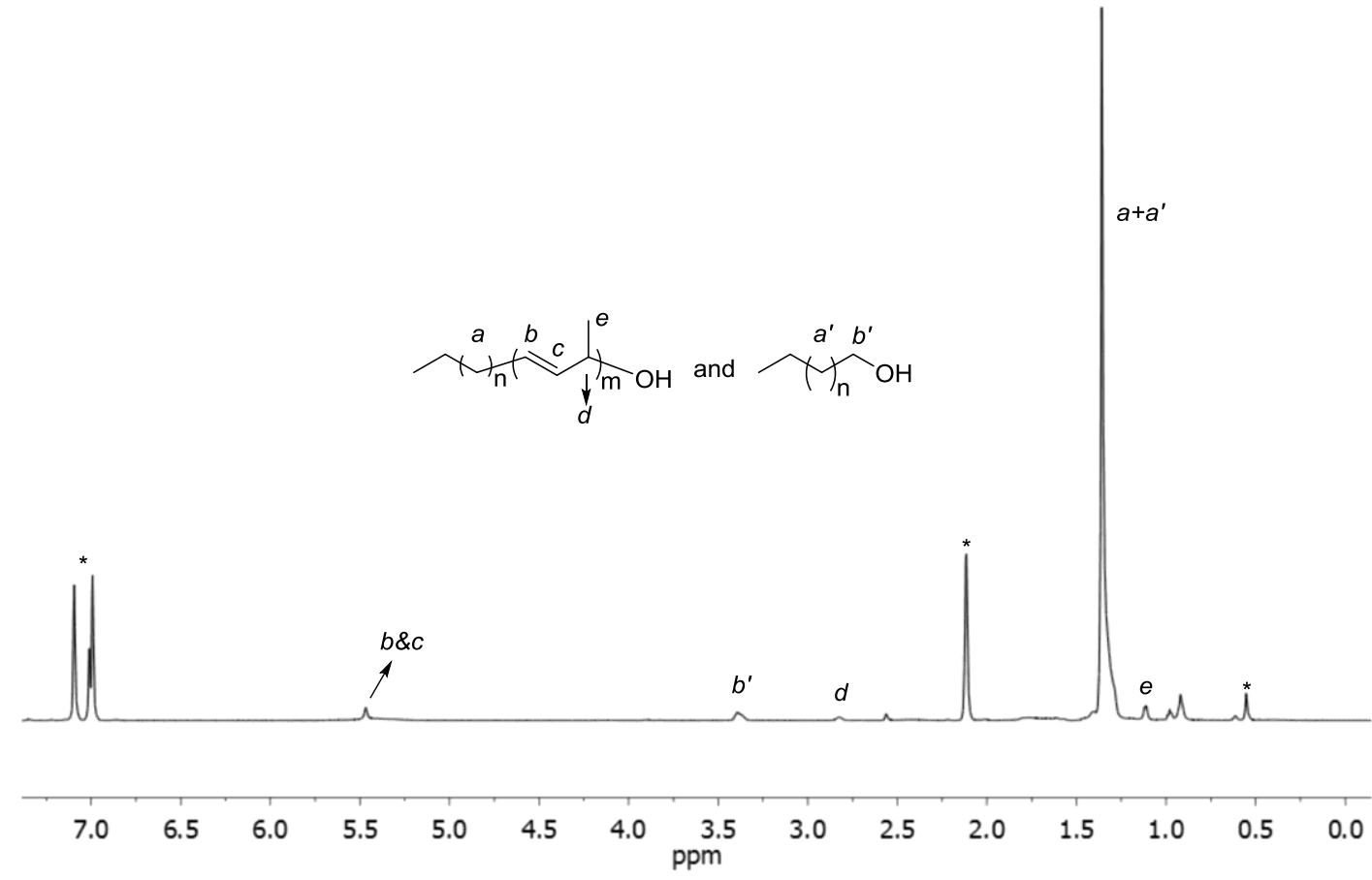

Figure S17. ${ }^{1} \mathrm{H}$ NMR spectrum $\left(600 \mathrm{M}\right.$, D8-toluene, $\left.80^{\circ} \mathrm{C}\right)$ of block copolymer 9 , mixed with PE-OH (the ratio of $9 / \mathrm{PE}-\mathrm{OH}$ is $2 / 1$ based on end group analysis, the signal at $2.5 \mathrm{ppm}$ is the residue DMSO)
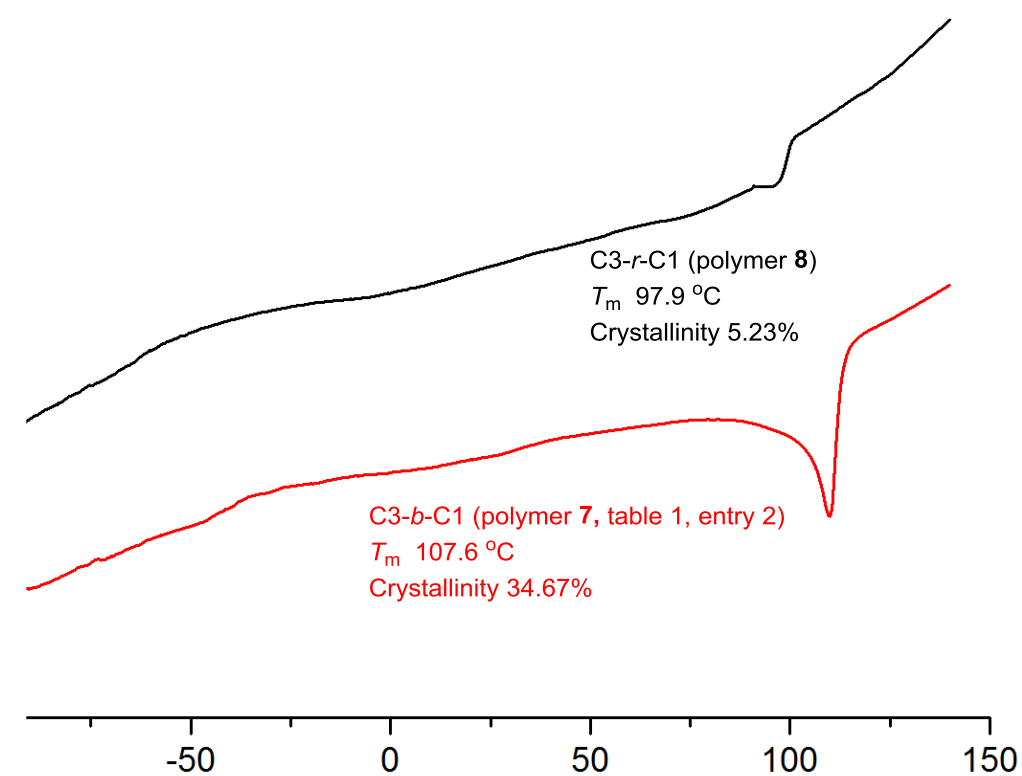

Figure S18. DSC traces for random and block copolymers. For the random copolymer 8, the melting temperature $T_{\mathrm{m}}=97.9{ }^{\circ} \mathrm{C}$ with crystallinity $5.23 \%$; for the block copolymer 7 , the melting $\mathrm{T}_{\mathrm{m}}=107.6{ }^{\circ} \mathrm{C}$ with crystallinity $34.67 \%$. The difference is attributed to the fact that the PE segments in polymer $\mathbf{8}$ is randomly distributed along the chain and in $\mathbf{7}$ are in one block. 